\title{
PENGGABUNGAN METODE ANALYTICAL HIERARCHY PROCESS DAN SIMPLE ADDITIVE WEIGHTING UNTUK PEMILIHAN SUPPLIER PADA SICI BUSANA
}

\author{
Prabowo Adi Pangestu ${ }^{1)}$, Anita Diana ${ }^{2)}$ \\ ${ }^{1}$ Sistem Informasi, Fakultas Teknologi Informasi, Universitas Budi Luhur \\ 1,2 Jl. Raya Ciledug, Petukangan Utara, Kebayoran Lama, Jakarta Selatan 12260 \\ E-mail : boypangestu.pap@gmail.com ${ }^{1}$, anita.diana@budiluhur.ac.id ${ }^{2}{ }^{2}$
}

\begin{abstract}
Abstrak
Pemilihan supplier merupakan salah satu kunci dalam aktivitas pembelian bagi perusahaan, aktivitas pembelian merupakan aktivitas yang memiliki nilai penting bagi perusahaan karena kesalahan dalam pemilihan supplier dapat berdampak pada terganggunya kelangsungan proses produksi. Adapun penelitian ini dilakukan untuk menyelesaikan masalah yang dihadapi oleh sici busana seperti sulit menentukan supplier, tidak optimalnya penilaian supplier, dan sulit mencari data supplier. Dengan adanya sistem pendukung keputusan diharapkan dapat membantu dalam proses pemilihan supplier dengan penilaian supplier dengan tepat dan akurat, Menghasilkan rancangan sistem penunjang keputusan pemilihan supplier yang dapat memberikan penilaian yang efektif bagi masing-masing alternatif, dan menyediakan laporan hasil proses pemilihan supplier untuk mempermudah analisis kriteria keputusan. Pada penelitian Sistem penunjang keputusan pemilihan supplier ini akan membantu pihak Sici Busana dalam melakukan proses pengambilan keputusan pemilihan supplier yang sesuai kriteria secara efektif sehingga dapat memberikan hasil maksimal bagi pihak Sici Busana.
\end{abstract}

Kata kunci: Sistem Penunjang Keputusan, Supplier, AHP, SAW

\section{PENDAHULUAN}

\subsection{Latar Belakang}

Pada proses pengambilan keputusan pemilihan supplier, dibutuhkan alat analisis yang berfungsi membantu penyelesaian masalah. Sehingga menciptakan suatu keputusan tepat dan akurat. Dengan menghasilkan rancangan sistem penunjang keputusan pemilihan supplier dapat memberikan penilaian yang efektif bagi masing-masing alternatif.

"Informasi adalah suatu data yang diolah menjadi bentuk baru yang berguna dan berarti bagi yang menerimanya. Sumber dari pada informasi adalah data. Data merupakan hal hal yang dapat menggambarkan suatu kejadian-kejadian dan bersifat faktual.” [1]

Proses pemilihan supplier yang kurang tepat akan mengakibatkan sulit menentukan supplier, keterlambatan barang yang dikirim, stok barang kosong, dan kerugian perusahaan. Dengan aplikasi sistem pendukung keputusan dalam memilih supplier diharapkan dapat membantu perusahaan dalam mengatasi masalah-masalah tersebut.

Tujuan dari penelitian ini adalah menentukan supplier yang paling cocok untuk digunakan sebagai pemasok dengan bantuan dari Simple Additive Weighting dan Analytical Hierarchy Process yang diharapkan dapat membantu melakukan proses pengambilan keputusan pemilihan suplier secara efektif sehingga dapat memberikan hasil maksimal bagi pihak Sici Busana

\subsection{Masalah Penelitian}

Berdasarkan permasalahan yang dialami Sici Busana dalam memilih supplier, maka penulis mengidentifikasi masalah sebagai berikut :

a. Sulit menentukan supplier pada Sici Busana karena tidak ada proses penilaian pasti .

b. Penilaian terhadap supplier belum optimal karena hanya sebatas diukur dari pendapat, perasaan dan perilaku masing masing alternatif.

c. Sulit mencari data supplier karena data para supplier tidak tercatat.

d. Tidak adanya laporan hasil evaluasi supplier, karena proses penilaian tidak tercatat.

e. Belum adanya rekap data penilaian supplier terpilih menggunakan database, karena masih menggunakan dokumen arsip.

\subsection{Tujuan Penelitian}

Adapun tujuan penelitian ini yaitu :

a. Membantu proses pemilihan supplier dengan penilaian supplier dengan tepat dan akurat.

b. Menghasilkan rancangan sistem penunjang keputusan pemilihan supplier yang dapat memberikan penilaian yang efektif bagi masing-masing alternatif.

c. Memberikan tempat penyimpanan data supplier yang diharapkan dapat membantu dalam proses pencarian supplier dengan cepat dan efisien. 
d. Menyediakan laporan hasil proses pemilihan supplier untuk mempermudah analisis kriteria keputusan.

e. Memberikan kemudahan dalam melihat data rekap supplier terpilih

\section{STUDI PUSTAKA}

\subsection{Sistem Penunjang Keputusan}

Sistem pendukung keputusan adalah alat bantu untuk mendukung pengambilan keputusan. Sistem pendukung keputusan memanfaatkan data, memberikan antarmuka pengguna yang mudah (user friendly), dan dapat menggabungkan pemikiran sang pengambil keputusan [2] .Fase-fase dalam proses pengambilan keputusan yaitu Penelusuran (Intellegence), Perancangan (Design), Pemilihan (Choice), dan Implementasi (Implementation).

\subsection{Analytical Hierarchy Process (AHP)}

Metode AHP menguraikan masalah mult kriteria yang kompleks menjadi sebuah hierarki. Intuisi manusia digunakan untuk menyelesaikan masalah yang kompleks yang struktur permasalahan tersebut tidak jelas dan tidak terdapat informasi statistik yang akurat [2]

\subsection{Simple Additive Weighting (SAW)}

Metode SAW atau metode penjumlahan terbobot memiliki konsep mencari penjumlahan terbobot dari rating kinerja alternatif pada semua atribut. Proses normalisasi matriks (x) dibutuhkan untuk dibandingkan dengan semua ranting alternatif yang ada [6] berikut:

Langkah penyelesaian SAW adalah sebagai

1) Menetukan kriteria-kriteria yang akan dijadikan acuan dalam pengambilan keputusan, yaitu Ci.

2) Menetukan rating kecocokan setiap alternatif pada setiap kriteria.

3) Membuat matriks keputusan berdasarkan kriteria (Ci), kemudian melakukan normalisasi matriks berdasarkan persamaan yang disesuaikan dengan jenis atribut (atribut keuntungan ataupun atribut biaya) sehingga diperoleh matriks ternormalisasi R.

4) Hasil akhir proses perankingan yaitu penjumlahan dari perkalian matriks ternormalisasi $\mathrm{R}$ dengan vektor bobot sehinggA diperoleh nilai terbesar yang dipilih sebagai alternatif terbaik (Ai) sebagai solusi.

$$
\mathrm{V}_{\mathrm{i}}=\sum_{\mathrm{j}=1}^{\mathrm{n}} W_{j} X R_{i j}
$$

Keterangan:

$\mathrm{Vi}$ = ranking untuk setiap alternatif
$\mathrm{Wj}=$ nilai bobot dari setiap kriteria

rij = nilai rating kinerja ternormalisasi Nilai Vi yang lebih besar mengidentifikasikan bahwa alternatif Ai lebih dipilih.

\subsection{Uml}

"UML adalah alat bantu yang menyediakan bahasa pemodelan visual yang memungkinkan bagi pengembang system(developer) untuk membuat cetak biru(blueprint) dalam bentuk yang baku dan mudah untuk dimengerti serta dilengkapi mekanisme yang efektif untuk berbagi (sharing) dan menghubungkan rancangan dengan pihak lain”[3]

\subsection{Fishbone}

"Fishbone analisis yang digunakan untuk memecahkan suatu masalah. Fungsi dasar dari diagram tulang ikan (fishbone) adalah untuk mengidentifikasi dan mengorganisasi penyebabpenyebab yang mungkin timbul dari suatu efek spesifik dan memisahkan akar penyebabnya”[1]

Adapun kategori-kategori yang terdapat pada diagram fishbone yaitu

Berikut kategori 6M yang digunakan dalam industri manufaktur :

a. Machine (teknologi atau mesin)

b. Method (proses atau metode)

c. Material (raw material, consumption, dan informasi)

d. Man Power (tenaga kerja atau pekerjaan fisik) / pekerjaan pikiran yaitu : saran dan sebagainya)

e. Measurement (pengukuran atau inspeksi)

f. Mother Nature/ Milieu (lingkungan)

Berikut kategori 8P yang digunakan dalam indsutri jasa:

a. Product (produk atau jasa)

b. Price (harga)

c. Place (tempat)

d. Promotion (hiburan atau promosi)

e. People (orang)

f. Process (proses)

g. Physical Evidence (bukti fisik)

h. Productivity \& Quality (produktivitas dan kualitas)

Kategori 5S yang biasa digunakan dalam industry jasa :

a. Surrounding (lingkungan)

b. Supplier (pemasok)

c. System (sistem)

d. Skill (keterampilan)

e. Safety (keselamatan)

\subsection{Studi Literatur}

Penelitian terkait tentang pemilihan supplier telah banyak dilakukan, beberapa diantaranya 
menggunakan metode Analytical Hierarchy Process (AHP) dan Simple Additive Weigting(SAW). Seperti penelitian yang dilakukan oleh [2] dalam jurnal ISSN 2597-3584 yang berjudul "Sistem Penunjang Keputusan Pemilihan Supplier pada Apotek dengan Metode AHP dan SAW (Studi Kasus Apotek XYZ)”. Apotek adalah perusahaan yang bergerak di bidang farmasi. Pada apotek, pemilihan supplier obat sangatlah penting, terutama untuk obat-obatan yang akan mereka jual ke pelanggan untuk menyembuhkan penyakit mereka. Apotek cenderung memiliki banyak supplier obat. Hal ini sering membuat apotek mendapat masalah dalam pemilihan supplier. Kesalahan dalam pemilihan supplier akan berdampak pada kualitas obat dan biaya yang dikeluarkan untuk membeli obat tersebut dari supplier. Oleh karena itu, mereka membutuhkan sebuah sistem penunjang keputusan yang dapat membantu memilih supplier terbaik secara akurat berdasarkan kriteria yang sudah ditentukan.

Penelitian selanjutnya dilakukan oleh [3] .dalam jurnal ISSN 2303-3363 “Metode AHP dan Promethee Untuk Sistem Pendukung Keputusan Pemilihan Supplier Obat” . Apotek merupakan salah satu jenis usaha di bidang kesehatan yang melakukan pekerjaan kefarmasian. Dengan jumlah kebutuhan obat yang begitu banyak, maka membutuhkan sebuah sistem yang dapat membantu perusahaan untuk mendukung proses pemilihan supplier. Pada makalah ini diusulkan gabungan metode AHP dan PROMETHEE sebagai pendukung model pengambilan keputusan untuk penetapan prioritas suatu sistem penilaian kinerja supplier.

\section{METODE PENELITIAN}

\subsection{Metode Pengumpulan Data}

Teknik pengumpulan data dalam penelitian sistem penunjang keputusan pemilihan supplier ini peneliti melakukannya dengan cara cara sebagai berikut : observasi, wawancara, analisis dokumen, kuesioner, dan studi literatur. Teknik pengumpulan data dilakukan sesuai dengan kondisi yang ada di lapangan.

\subsection{Teknik Analisis Data}

Teknik Analisis Data yang digunakan yaitu analisis deskriptif, Analytical Hierarchy Process (AHP), dan Simple Additive Weighting (SAW). Analisis deskriptif digunakan untuk menciptakan suatu kesimpulan dan gambaran tentang proses bisnis yang berjalan pada Sici Busana. Sedangkan Analytical Hierarchy Process (AHP) digunakan untuk kepastian penentuan bobot dari setiap kriteria yang karena Sici Busana belum memberikan pembobotan kriteria. Penggunaan metode Simple Additive Weighting (SAW) berfugsi untuk mengurutkan alternatif-alternatif setelah pengolahan kriteria dan untuk menentukan perangkingan supplier yang diurutkan dari nilai terbesar ke nilai terkecil agar dapat diperoleh hasil perankingan untuk mengetahui kandidat supplier yang memiliki hasil penilaian terbaik.

\subsection{Kerangka Pemikiran}

Kerangka pemikiran penulis gambarkan pada Gambar 1. Awal pemikiran dilakukan dengan Studi lapangan, wawancara, dan Studi Pustaka. Setelah melakukan Studi lapangan, wawancara, dan Studi Pustaka penulis mendapatkan informasi terkait permasalahan dan proses berjalan dalam pemilihan supplier. Kemudian melakukan tahap pengumpulan data dengan mengumpulkan dokumen-dokumen berjalan pada Sici Busana. merancang kuesioner berdasarkan kriteria yang berlaku untuk pemilihan supplier. Selanjutnya melakukan analisis data dari data yang sudah didapat dengan penggabungan dua metode

Analytical Hierarchy Process (AHP) dan metode Simple Additive Weighting (SAW) yang kemudian akan diperoleh bobot kepentingan dari masing-masing kriteria. Lalu tahap selanjutnya adalah mendesain model dan desain prototype. Setelah itu dilakukan pembuatan laporan dan akan diketahui penilaian dari masing-masing supplier yang dapat menunjang pengambilan keputusan pemilihan supplier yang dilakukan oleh Decision Maker.

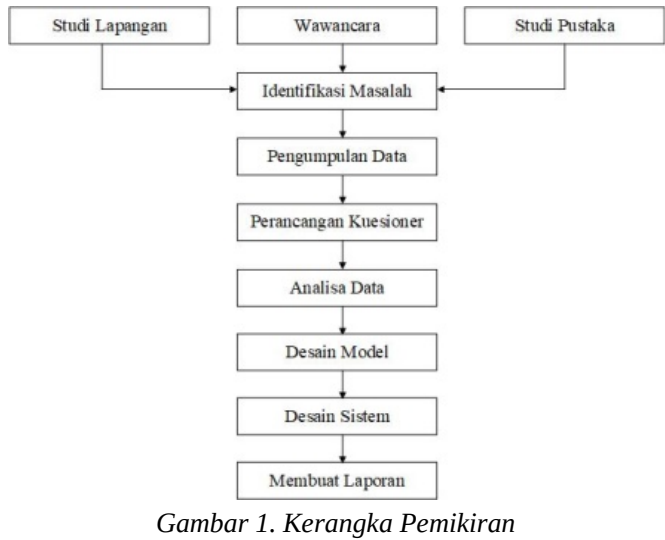

\section{HASIL DAN PEMBAHASAN}

\subsection{Analisis Masalah}

Dalam analisis masalah pada pengambilan keputusan untuk menentukan Supplier yang akan dipilih, penulis menyajikan fishbone diagram atau diagram Ishikawa yang menjelaskan analisis masalah pada gambar 2 . 


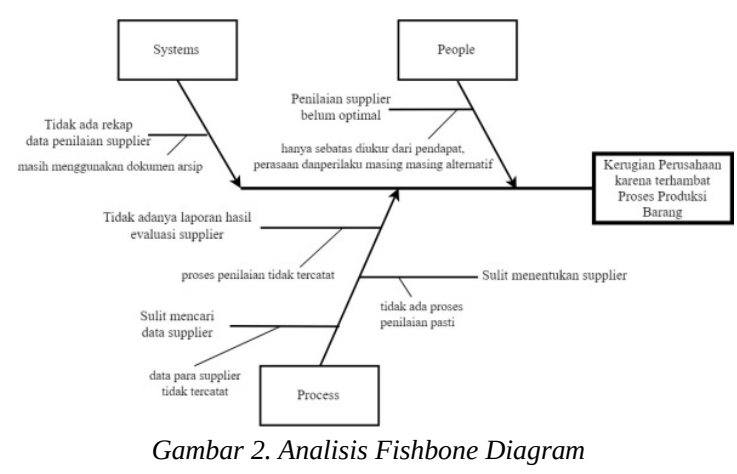

\subsection{Analisis Proses Bisnis}

Admin barang menghubungi kandidat supplier untuk meminta salah satu sample pakaian yang nantinya akan dibeli kepada supplier. Lalu supplier mengirimkan sample pakaian. Bagian barang akan memeriksa bahan pakaian. Jika bahan sample bagus, admin barang akan lanjut menilai sample dari model pakaian. Jika bahan dan model yang digunakan pada sample cocok dan bagus, maka supplier tersebut berhak meneruskan proses evaluasi kandidat supplier. Admin barang akan menanyakan 3 hal yaitu diskon yang ditawarkan, tempo pembayaran dan waktu pengiriman. Jika diskon lebih dari $25 \%$ maka dianggap berhak meneruskan evaluasi supplier, tetapi jika diskon yang ditawarkan lebih rendah dari 25\% maka supplier tersebut tidak berhak menjadi kandidat. Selanjutnya mengecek berapa lama tempo pembayaran, jika durasi pembayaran lebih atau sama dengan dari 30 hari maka supplier tersebut berhak meneruskan evaluasi supplier, tetapi jika kurang dari 30 hari maka tidak berhak meneruskan evaluasi supplier. Selanjutnya admin barang menanyakan durasi pengiriman, jika pengiriman dapat dilakukan kurang dari 30 hari maka supplier tersebut berhak meneruskan evaluasi tetapi jika durasi pengiriman lebih dari 30 hari maka supplier tidak dapat meneruskan evaluasi.

Setelah mengevaluasi proses pemesanan maka akan tersisa supplier yang lolos dari semua kriteria yang ada dan dapat dijadikan sebagai calon supplier terpilih.

\subsection{Struktur hierarki}

AHP mempergunakan model hierarki yang terdiri dari tujuan, kriteria, beberapa subkriteria dan alternatif untuk masalah yang dihadapi. Dengan digunakannya hierarki, permasalahan yang kompleks dapat dijabarkan menjadi elemen-elemen yang lebih sederhana dan mudah dimengerti. Penulis menjabarkan hierarki studi kasus Sici Busana pada Gambar 3.

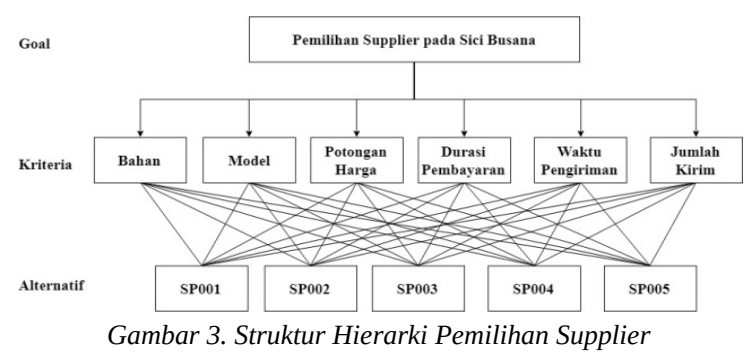

\subsection{Perhitungan Bobot Kriteria}

Tabel 1. Perbandingan Kriteria

\begin{tabular}{lllllll}
\hline KRITERIA & KT1 & KT2 & KT3 & KT4 & KT5 & KT6 \\
\hline KT1 & 1 & 1 & 2 & $1 / 2$ & $1 / 4$ & 5 \\
KT2 & 1 & 1 & 1 & $1 / 2$ & $1 / 3$ & 3 \\
KT3 & $1 / 2$ & 1 & 1 & 2 & $1 / 6$ & 2 \\
KT4 & 2 & 2 & $1 / 2$ & 1 & $1 / 2$ & 6 \\
KT5 & 4 & 3 & 6 & 2 & 1 & 6 \\
KT6 & $1 / 5$ & $1 / 3$ & $1 / 2$ & $1 / 6$ & $1 / 6$ & 1 \\
\hline
\end{tabular}

Diperoleh hasil perhitungan metode AHP yang kemudian dijadikan bobot masing masing kriteria sebagai berikut

Tabel 2. Bobot Kriteria

\begin{tabular}{ll}
\hline KRITERIA & BOBOT \\
\hline Bahan & 0,136 \\
Model & 0,113 \\
Potongan Harga & 0,125 \\
Durasi Pembayaran & 0,191 \\
Waktu Pengiriman & 0,394 \\
Jumlah Kirim & 0,041 \\
\hline
\end{tabular}

Bobot dari setiap kriteria yang diambil dari eigenvector hasil perhitungan

\subsection{Perankingan Alternatif}

Diambil lima supplier sebagai contoh untuk penerapan dengan metode Simple Additive Weighting (SAW) dalam penentuan supplier. Calon supplier memiliki data sebagai berikut.

Tabel 3. DataNilai Alternatif

\begin{tabular}{lllllll}
\hline & KT1 & KT2 & KT3 & KT4 & KT5 & KT6 \\
\hline SP1 & 3 & 3 & 1000 & 33 & 7 & 2 \\
SP2 & 4 & 4 & 3000 & 33 & 7 & 2 \\
SP3 & 4 & 4 & 5000 & 91 & 7 & 1 \\
SP4 & 4 & 3 & 3000 & 62 & 7 & 2 \\
SP5 & 4 & 3 & 3000 & 30 & 7 & 1 \\
\hline
\end{tabular}

dilakukan normalisasi untuk menghitung nilai masing-masing kriteria

Tabel 4. Hasil Normalisasi

\begin{tabular}{lllllll}
\hline & KT1 & KT2 & KT3 & KT4 & KT5 & KT6 \\
\hline SP1 & 0,75 & 0,75 & 0,2 & 0,363 & 1 & 1 \\
SP2 & 1 & 1 & 0,6 & 0,363 & 1 & 1 \\
SP3 & 1 & 1 & 1 & 1 & 1 & 0,5 \\
SP4 & 1 & 0,75 & 0,6 & 0,681 & 1 & 1 \\
SP5 & 1 & 0,75 & 0,6 & 0,363 & 1 & 0,5 \\
\hline
\end{tabular}


Setelah nilai normalisasi dan melihat nilai bobot pada perhitungan AHP, selanjutnya merupakan langkah proses prefensi (Vi) dengan menggunakan formula :

$$
V_{i}=\sum_{j=1}^{n} w_{j} r_{i j}
$$

Bobot $(\mathrm{W})=[\mathbf{0 , 1 3 6} ; \mathbf{0 , 1 1} ; \mathbf{0 , 1 2 5} ; \mathbf{0 , 1 9 1 ; 0 , 3 9 4 ;}$ 0,041]

$$
\begin{aligned}
\text { Yes } & =(0,75 \times 0,136)+(0,75 \times 0,113)+(0,2 \times 0,125)+ \\
& (0,363 \times 0,191)+(1 \times 0,394)+(1 \times 0,041) \\
& =0,716
\end{aligned}
$$

Sumber Inti Perkasa $=(1 \times 0,136)+(1 \times 0,113)+$ $(0,6 \times 0,125)+(0,363 \times 0,191)+(1 \times 0,394)+(1 \times$ $0,041)=0,828$

Mahkota Maharani $=(1 \times 0,136)+(1 \times 0,113)$ $+(1 \times 0,125)+(1 \times 0,191)+(1 \times 0,394)+(0,5 \times 0$, 041) $=0,98$

Adit Collection $=(1 \times 0,136)+(0,75 \times 0,113)+$ $(0,6 \times 0,125)+(0,681 \times 0,191)+(1 \times 0,394)+(1 \times$ $0,041)=0,861$

Tini Fashion $=(1 \times 0,136)+(0,75 \times 0,113)$ $+(0,6 \times 0,125)+(0,33 \times 0,191)+(1 \times 0,394)+(0$, $5 \times 0,041)=0,773$

Tabel 5. Hasil Nilai Alternatif

\begin{tabular}{lll}
\hline Alternatif & Hasil Perhitungan & Rank \\
\hline Mahkota Maharani & 0,98 & 1 \\
Adit Collection & 0,861 & 2 \\
Sumber Inti Perkasa & 0,828 & 3 \\
Tini Fashion & 0,773 & 4 \\
Yes & 0,716 & 5 \\
\hline
\end{tabular}

Setelah melakukan perhitungan diatas maka dapat disimpulkan bahwa Mahkota Maharani adalah Supplier yang memiliki nilai terbaik dengan perolehan nilai 0,98. tetapi yang berhak menentukan adalah Decision Maker.

\subsection{Use Case Diagram}

Merupakan Diagram yang menggambarkan suatu diagram yang berisi actor, use case, dan relasi menjadi suatu nilai tindakan pada sistem

a. Use Case Diagram Master

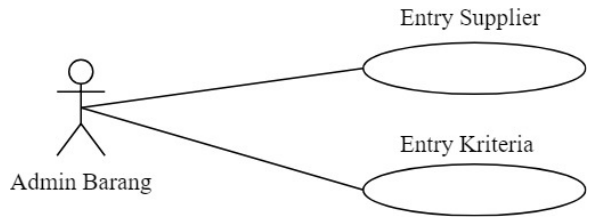

Gambar 4. Use Case Diagram Master

b. Use Case Diagram Transaksi

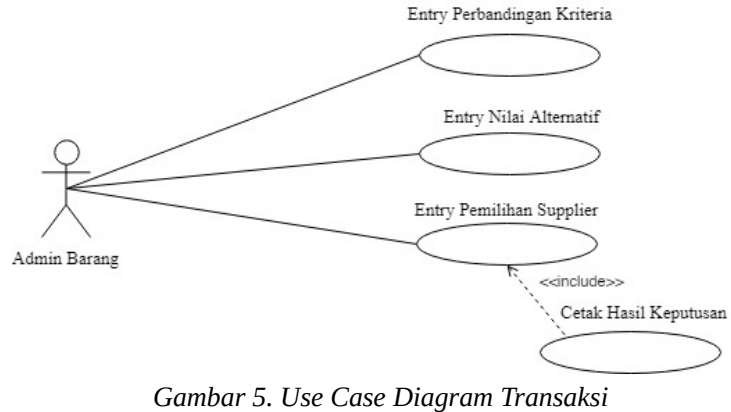

c. Use Case Diagram Laporan

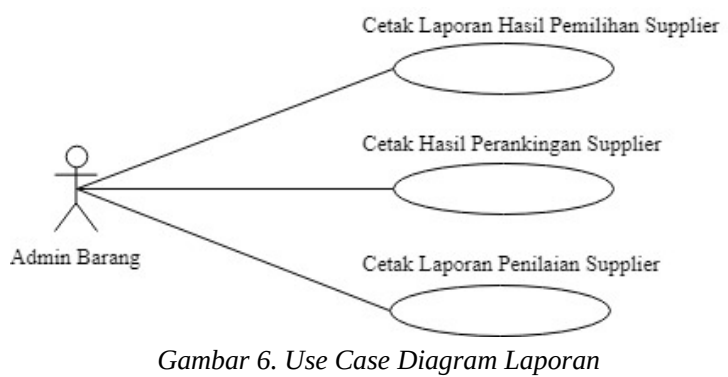

\subsection{Pemodelan Data}

Perancangan basis data penulis gambarkan dengan Entity Relationship Diagram (ERD) pada gambar 7.

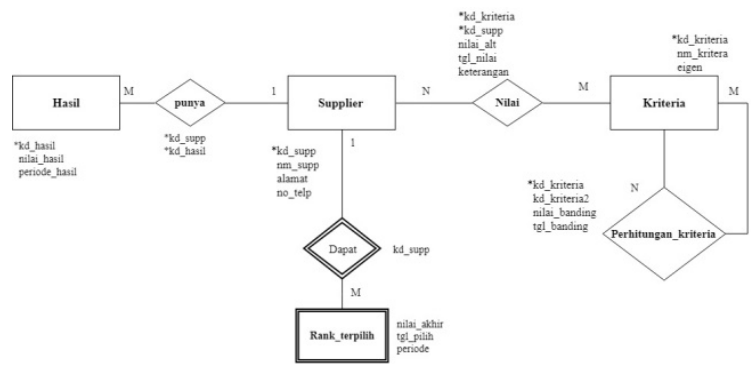

Gambar 7. Rancangan Entity Relationship Diagram (ERD)

\subsection{Rancangan Layar}

1) Rancangan Layar Menu Utama (Dashboard)

Pada Gambar 8. terdapat menu seperti Master, Transaksi, dan Laporan

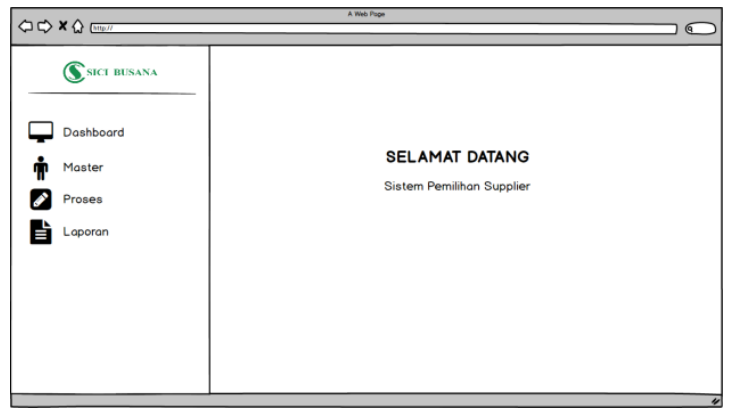

Gambar 8. Rancangan Layar Menu Utama 
2) Rancangan Layar Perbandingan Kriteria

Pada Gambar 9. terdapat menu untuk mengentry nilai perbandingan antar kriteria

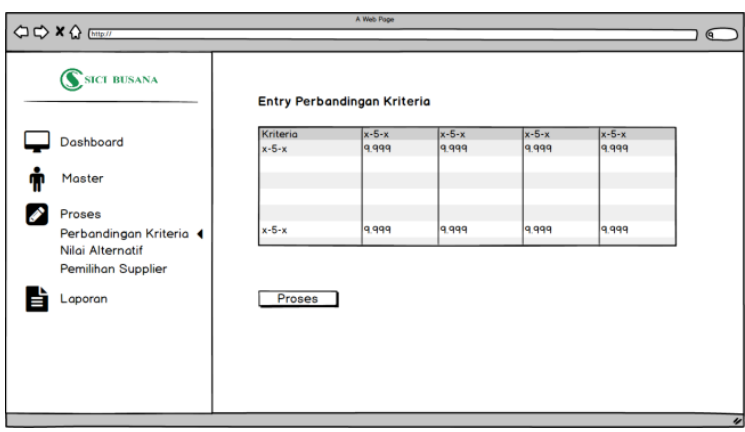

Gambar 9. Rancangan Layar Entry Perbandingan Kriteria

3) Rancangan Layar Nilai Alternatif

Pada Gambar 10. terdapat menu untuk untuk mengentry data nilai alternatif .

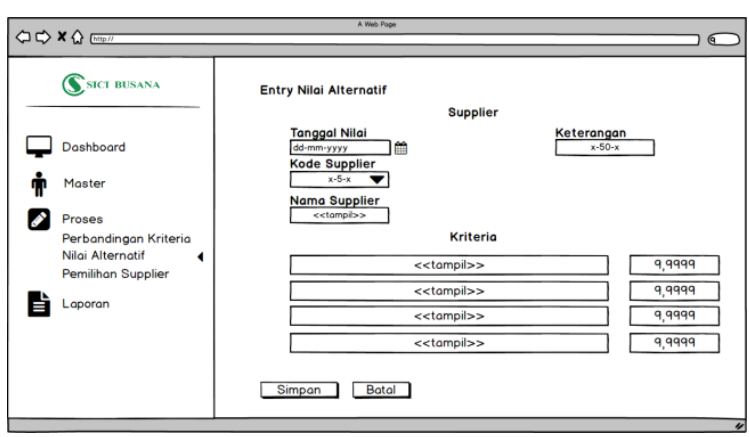

Gambar 10. Rancangan Layar Entry Penilaian Alternatif

4) Rancangan Layar Pemilihan Supplier

Pada Gambar 11. terdapat untuk menentukan keputusan pemilihan supplier dari data penilaian supplier yang sudah dihitung.

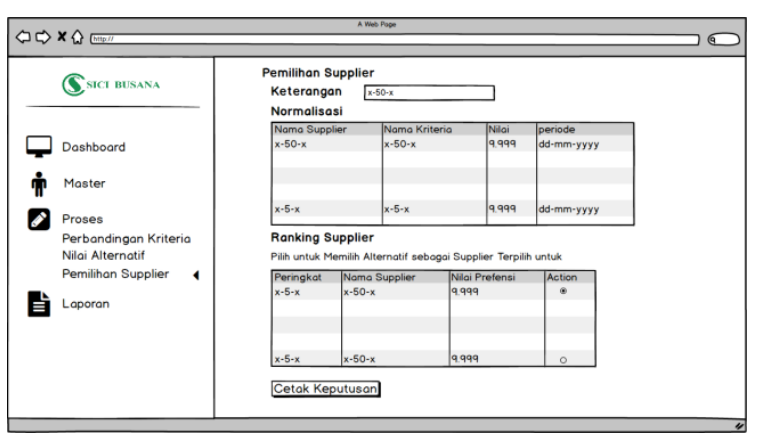

Gambar 11. Rancangan Layar Entry Pemilihan Supplier

\subsection{Sequence Diagram}

1) Sequence Diagram Perbandingan Kriteria

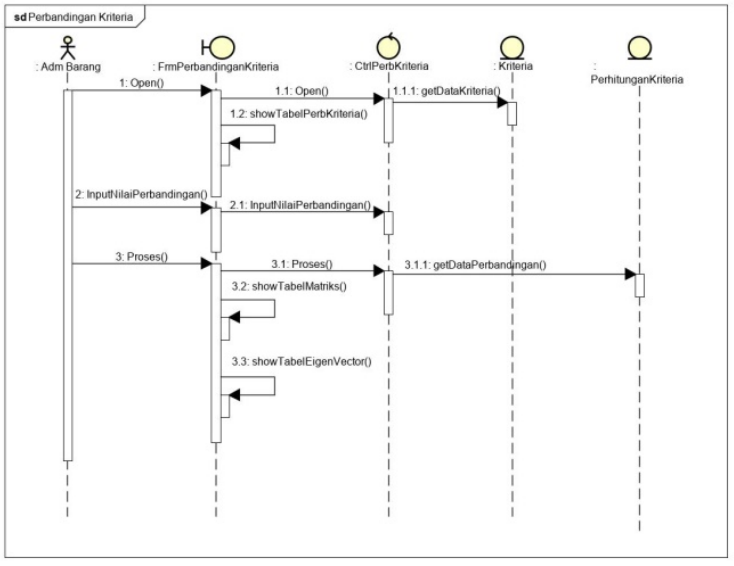

Gambar 12. Sequence Diagram Perbandingan Kriteria

2) Sequence Diagram Penilaian Alternatif

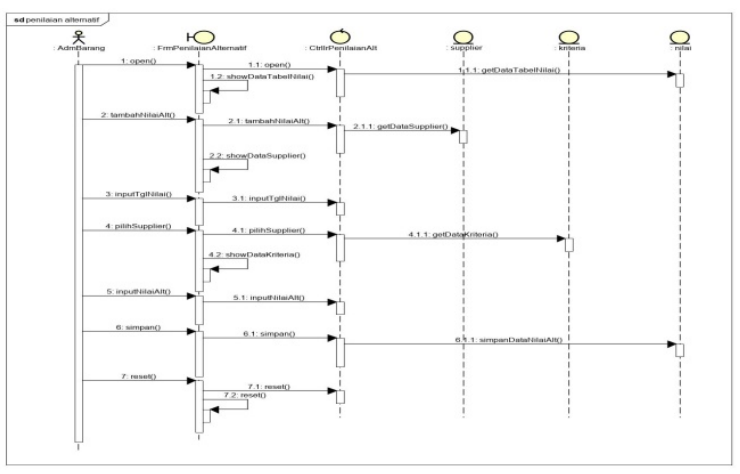

Gambar 13. Sequence Diagram Pemilihan Supplier

3) Sequence Diagram Pemilihan Supplier

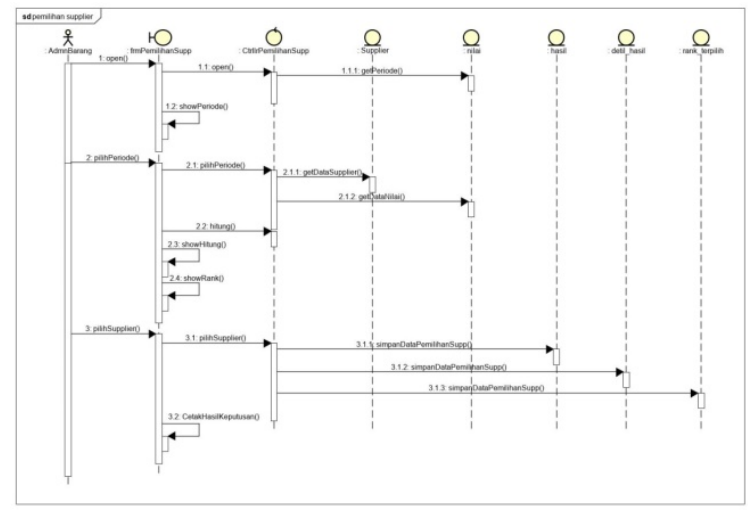

Gambar 14. Sequence Diagram Pemilihan Supplier

\subsection{Class Diagram}

Gambar 15. merupakan Class Diagram pada rancangan SPK Sici Busana 


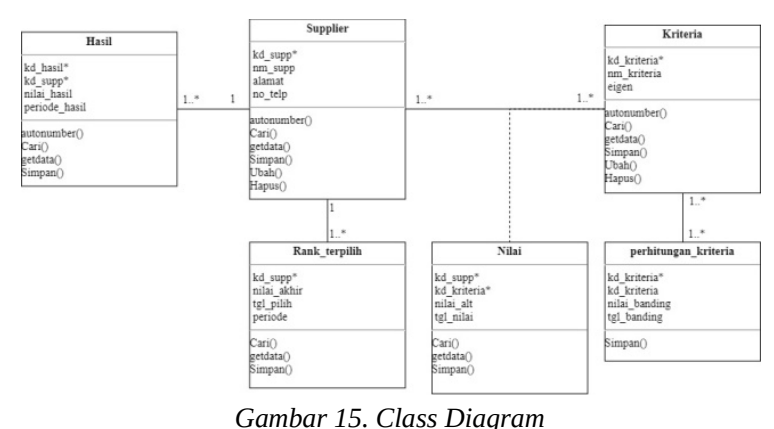

\section{KESIMPULAN}

Adapun kesimpulan sistem penunjang keputusan pemilihan supplier pada sici busana yaitu :

a. Dengan menggabungkan metode perhitungan AHP dengan SAW, diharapkan memberikan solusi dan perhitungan penilaian supplier dengan tepat dan akurat.

b. Dengan adanya sistem penunjang keputusan pada proses penilaian alternatif diharapkan dapat memberikan penilaian yang efektif bagi masing-masing alternatif.

c. Dengan adanya penyimpanan database , diharapkan dapat membantu dalam proses pencarian supplier dengan cepat dan efisien.

d. Dengan adanya sistem penunjang keputusan, dapat menyediakan laporan pemilihan supplier utnuk mempermudah analisis kriteria dan evaluasi supplier.

e. Dengan adanya penyimpanan rekap data penilaian supplier dengan database, diharapkan dapat mempermudah dalam melihat rekap penilaian supplier dan meminimalisir adanya kehilangan data.

Adapun Saran mengenai Sistem Penunjang Keputusan Pemilihan Supplier pada Sici Busana yaitu :

a. Dalam proses penginputan data dan nilai dalam penilaian supplier dibutuhkan ketelitian agar hasil keputusan dilakukan secara maksimal dan menghasilkan laporan sesuai kebutuhan

b. Sistem penunjang keputusan ini memerlukan sebuah pelatihan (training) kepada user yang akan menggunakan sistem agar sistem beroperasi dengan benar.

\section{DAFTAR PUSTAKA}

[1] A. Nugroho Santoso, Jurus Jitu membangun Bisnis Berkah Omset Milyaran. Yogyakarta: PT Vindra Sushantco Putra, 2015.
[2] A. Y. Pradipta and A. Diana, "Sistem Penunjang Keputusan Pemilihan Supplier pada Apotek dengan Metode AHP dan SAW (Studi Kasus Apotek XYZ)," Sisfotek, vol. 3584, pp. 107-114, 2017.

[3] D. Apriliani, N. Fauziah, and R. Riyanto, "Metode AHP dan Promethee Untuk Sistem Pendukung Keputusan Pemilihan Supplier Obat,” vol. 17, no. 2, pp. 42-47, 2018.

[4] S. Abadi and F. Latifah, "Decision Support System Penilaian Kinerja Karyawan Pada Perusahaan Menggunakan Metode Simple Additive Weighting," J. TAM (Technology Accept. Model., vol. 6, pp. 3743, 2016.

[5] S. Hidayat and S. Noor, "PENGEMBANGAN SISTEM INFORMASI DESA TERINTEGRASI," vol. IV, no. 2, pp. 191-198, 2018.

[6] T. Supriyatna and Suwarni, "Perancangan dan Implementasi Sistem Informasi Akuntansi Berbasis Android,” J. Infotel, vol. 9, no. 3, pp. 304-312, 2017. 